\title{
A randomized, double-blind, and placebo-controlled study with tranexamic acid of bleeding and fibrinolytic activity after primary coronary artery bypass grafting
}

\author{
A.T.L. Santos, R.A.K. Kalil, \\ C. Bauemann, J.B. Pereira ${ }^{+}$ \\ and I.A. Nesralla
}

Instituto de Cardiologia do Rio Grande do Sul,

Fundação Universitária de Cardiologia, Porto Alegre, RS, Brasil
Correspondence

A.T.L. Santos

Unidade de Pesquisa

Instituto de Cardiologia do

Rio Grande do Sul

Av. Princesa Isabel, 395

90620-001 Porto Alegre, RS, Brasil

Fax: +55-51-3230-3600

E-mail: pesquisa@cardiologia.org.br

†In memoriam

Research supported in part by FAPERGS and Fundo de Apoio à

Pesquisa do Instituto de Cardiologia do Rio Grande do Sul - Fundação

Universitária de Cardiologia.

Received June 24, 2004 Accepted August 16, 2005

\begin{abstract}
Cardiopulmonary bypass is frequently associated with excessive blood loss. Platelet dysfunction is the main cause of non-surgical bleeding after open-heart surgery. We randomized 65 patients in a double-blind fashion to receive tranexamic acid or placebo in order to determine whether antifibrinolytic therapy reduces chest tube drainage. The tranexamic acid group received an intravenous loading dose of $10 \mathrm{mg} /$ $\mathrm{kg}$, before the skin incision, followed by a continuous infusion of $1 \mathrm{mg}$ $\mathrm{kg}^{-1} \mathrm{~h}^{-1}$ for $5 \mathrm{~h}$. The placebo group received a bolus of normal saline solution and continuous infusion of normal saline for $5 \mathrm{~h}$. Postoperative bleeding and fibrinolytic activity were assessed. Hematologic data, convulsive seizures, allogeneic transfusion, occurrence of myocardial infarction, mortality, allergic reactions, postoperative renal insufficiency, and reopening rate were also evaluated. The placebo group had a greater postoperative blood loss (median (25th to 75th percentile) $12 \mathrm{~h}$ after surgery (540 (350-750) vs $300(250-455) \mathrm{mL}, \mathrm{P}$ $=0.001)$. The placebo group also had greater blood loss $24 \mathrm{~h}$ after surgery (800 (520-1050) vs $500(415-725) \mathrm{mL}, \mathrm{P}=0.008)$. There was a significant increase in plasma D-dimer levels after coronary artery bypass grafting only in patients of the placebo group, whereas no significant changes were observed in the group treated with tranexamic acid. The D-dimer levels were 1057 (1025-1100) $\mu \mathrm{g} / \mathrm{L}$ in the placebo group and $520(435-837) \mu \mathrm{g} / \mathrm{L}$ in the tranexamic acid group $(\mathrm{P}=0.01)$. We conclude that tranexamic acid effectively reduces postoperative bleeding and fibrinolysis in patients undergoing first-time coronary artery bypass grafting compared to placebo.
\end{abstract}

Key words - Tranexamic acid - Coronary artery bypass - Postoperative bleeding - Clinical trial

\section{Introduction}

In 1953, John Gibbon performed the first successful open-heart operation on a human patient using a heart-lung machine, starting the age of open-heart surgery. Blood require- ments per cardiac case in the early 1950's were 20 to 30 units (1). Despite continuous advances improving the safety of cardiac surgery, excessive bleeding requiring transfusion of blood components after cardiopulmonary bypass (CPB) is still one of the main causes of 
postoperative morbidity (2).

Pericardial blood activates the extrinsic coagulation pathway and nonendothelialized materials in the extracorporeal circuit activate the intrinsic coagulation pathway during CPB. Despite systemic doses of heparin, thrombin generation is observed during $\mathrm{CPB}$ (3). Thrombin not only converts fibrinogen to fibrin, but is also the most powerful platelet activator. It activates the endothelium and fibrinolysis via the release of tissue plasminogen activator from the endothelium. Consequently, generalized fibrinolysis occurs during and immediately after $\mathrm{CPB}$, as reflected by increased plasmin concentrations and fibrin degradation products, both of which have deleterious effects on platelet function (4-6). Increased fibrinolytic activity and platelet dysfunction have been identified as important factors of postoperative bleeding (7).

Antifibrinolytic drugs are used to prevent platelet dysfunction and to decrease perioperative bleeding. Recently, there has been increased interest in tranexamic acid (TA) as an alternative to the more expensive drug aprotinin. TA acts by forming a reversible complex with plasminogen and plasmin through the lysine-binding sites, thus blocking interaction with the specific lysine residues of fibrin. This process retards fibrinolysis because, although plasmin is still formed, it is unable to bind to fibrin (8). TA also preserves platelet function by reducing the effect of plasmin on platelet glycoprotein $1 \mathrm{~b}$ receptors (9).

The aim of the present study was to determine the hemostatic and antifibrinolytic effect of TA in primary coronary artery bypass grafting (CABG).

\section{Material and Methods}

A prospective, randomized, placebo-controlled, double-blind trial was designed to determine the antifibrinolytic and hemostatic effect of TA in CABG. After approval of the study by the Hospital Ethics Committee, 65 patients undergoing primary non-emergent CABG who gave written informed consent to participate were enrolled. The groups were randomized by means of sequentially numbered sealed envelopes opened by a nurse in the operating room. This method ensured that only the nurse, who prepared the infusions, knew whether a patient received drug or placebo. Criteria for preoperative exclusion included cardiac surgery reoperation, renal insufficiency (plasma creatinine concentration higher than $2 \mathrm{mg} / \mathrm{kg}$ ), and a history of hematological disorders, hepatic dysfunction or antiplatelet therapy within seven days of surgery.

The enrolled patients were assigned randomly to the TA or placebo group. The TA group received an intravenous loading dose of $10 \mathrm{mg} / \mathrm{kg}$ TA (Transamin; Química e Farmacêutica Nikkho do Brasil, Rio de Janeiro, RJ, Brazil) before the skin incision, followed by a continuous infusion of $1 \mathrm{mg}$ $\mathrm{kg}^{-1} \mathrm{~h}^{-1}$ for $5 \mathrm{~h}$. The placebo group received a bolus of normal saline solution in an identical syringe and continuous infusion of normal saline for $5 \mathrm{~h}$. The drugs were delivered in identical volumes. The staff in the operating room and in the intensive care unit were not aware of the treatment.

The anesthetic protocol consisted of intravenous thiopental, fentanyl citrate and pancuronium bromide. Maintenance of anesthesia was obtained with fentanyl citrate and halothane or isoflurane. Exposure was provided by a median sternotomy. CPB was performed with an Oxim II-34 Ultra membrane oxygenator (Edwards Lifesciences, Irvine, CA, USA) and a Sarns CPB machine (Sarns, Ann Arbor, MI, USA) at a flow of $2.6 \mathrm{~L} \mathrm{~min}^{-1} \mathrm{~m}^{-2}$, under moderate systemic hypothermic conditions $\left(28-30^{\circ} \mathrm{C}\right)$. Systemic heparinization was performed before $\mathrm{CPB}$ with heparin (Liquemine, $5000 \mathrm{IU} / \mathrm{mL}$; Produtos Roche Químicos e Farmacêuticos S/A, São Paulo, SP, Brazil) at the dose of $400 \mathrm{IU} / \mathrm{kg}$ and was reversed at the end of 
CPB with protamine (Protamina 1000, 10 mg/mL; Produtos Roche Químicos e Farmacêuticos) at the dose of $4 \mathrm{mg} / \mathrm{kg}$. During CPB the activated coagulation time (ACT) was maintained higher than $600 \mathrm{~s}$.

The mass of blood collected via mediastinal and pleural drains for a period beginning with chest closure and lasting $24 \mathrm{~h}$ represented blood loss. The total volume of mediastinal blood shed after the operation was measured hourly, without knowledge of the study group. Bleeding was defined as excessive if greater than $750 \mathrm{~mL} / 24 \mathrm{~h}$. Administration of blood depended on bleeding, hemodynamic and laboratory data. Red blood cell (RBC) concentrates were transfused when hemoglobin $(\mathrm{Hb})$ concentration was less than $7 \mathrm{~g} / \mathrm{dL}$. Old patients (more than 70 years old) were transfused when $\mathrm{Hb}$ concentration was less than $10 \mathrm{~g} / \mathrm{dL}$. The amount of $\mathrm{RBC}$ given to each patient was recorded. A cell salvage device was not used during the operation and postoperative period.

To assess the fibrinolytic activity in the two groups, quantitative D-dimer concentrations were measured in the first $41 \mathrm{pa}-$ tients after induction of anesthesia and $3 \mathrm{~h}$ after termination of CPB (serum D-dimer levels were measured in 41 patients because we only had one kit). Blood samples were collected into citrate-containing vacutainer tubes and centrifuged and plasma was frozen until the time of assay for D-dimer concentration using the Asserachrom D-Di kit (normal $400 \mu \mathrm{g} / \mathrm{L}$; Diagnostica Stago, Ashieres-Sour-Seine, France).

Preoperative laboratory tests included $\mathrm{Hb}$, hematocrit (Ht), platelet count, prothrombin time (PT), activated partial thromboplastin time (aPTT), and plasma creatinine levels. ACT was recorded before and after heparin administration, every $60 \mathrm{~min}$ during $\mathrm{CPB}$ and after protamine infusion. Before heparin administration and after protamine infusion, coagulation assessment included PT, aPTT, plasma fibrinogen, and thrombin time. $\mathrm{Hb}$ and $\mathrm{Ht}$ levels were determined before and after CPB and $24 \mathrm{~h}$ after the operation.

Other clinical outcomes were also analyzed, such as reopening rates, myocardial infarction (new persistent Q-wave and creatine kinase myocardial-band levels more than $30 \mathrm{U} / \mathrm{mL}$ ), acute renal insufficiency (plasma creatinine concentration higher than $2 \mathrm{mg} /$ $\mathrm{kg}$ ), number of RBC transfusions, allergic reactions, convulsive seizures, mortality, and stroke (stroke as neurologic complication was defined by hemiparesis, hemiplegia, aphasia, or confusion and disorientation).

The sample size calculation was based on retrospective data from our institution showing that 10 consecutive patients undergoing primary, non-emergent CABG had an average postoperative blood loss of $840 \mathrm{~mL}$. On the basis of a clinically relevant blood loss difference of $250 \mathrm{~mL}(30 \%)$ and an standard deviation of $300 \mathrm{~mL}$, we determined a sample size of 24 patients in each group with a power of $80 \%$ and a type 1 error of $5 \%$.

Analysis was performed following the "on treatment" rule, by accepting that noncompliance and protocol deviations were unlikely to occur in this kind of trial.

The Kolmogorov-Smirnov test was used to test the normality of the distribution of the continuous variables. Nonparametric as well as non-normally distributed data are reported as median and 25th to 75 th percentiles and were evaluated by the Mann-Whitney Utest. Normally distributed data were analyzed by the Student $t$-test or by analysis of variance for repeated measures (ANOVA) and are reported as means \pm SD. Categorical data were analyzed by the chi-square test. A $P$ value less than 0.05 was considered to be statistically significant.

Data were analyzed using the commercial statistical package SPSS for Windows ${ }^{\circledR}$, Version 11.0 (SPSS Inc., Chicago, IL, USA).

\section{Results}

From March 19, 2001, to June 18, 2001, 
65 patients were enrolled into the two groups and 60 patients completed the study according to protocol and were considered for statistical analysis. Five patients were excluded from the sample before analysis due to protocol violation. Two patients in the TA group and 2 patients in the placebo group were excluded from the study because they had received the loading dose after heparin administration. One patient in the TA group was excluded because he underwent combined intervention of coronary revascularization and aortic valve replacement and the blood samples were taken at irregular intervals.

The study groups were comparable with respect to demographic and baseline characteristics (Table 1). The two groups were also homogeneous with respect to preoperative laboratory data including $\mathrm{Ht}, \mathrm{Hb}, \mathrm{PT}$, aPTT, platelets, and creatinine and there were no significant differences between groups in

Table 1. Demographic and baseline characteristics of the patients studied.

\begin{tabular}{lcc}
\hline Variable & Tranexamic acid (N = 29) & Placebo (N = 31) \\
\hline Gender (\% male) & $62.1 \%$ & $80.6 \%$ \\
Age (years) & $62 \pm 9.2$ & $59 \pm 8.7$ \\
Weight $(\mathrm{kg})$ & $76 \pm 14.1$ & $74 \pm 14.3$ \\
Height $(\mathrm{cm})$ & $165 \pm 3.2$ & $165 \pm 9.4$ \\
Previous myocardial infarction (N) & $13(44.8 \%)$ & $13(41.9 \%)$ \\
Diabetes (N) & $14(48.3 \%)$ & $8(25.8 \%)$ \\
Previous hypertension (N) & $19(65.5 \%)$ & $15(48.4 \%)$ \\
Ejection fraction (\%) & $75 \%(58-80.5)$ & $75 \%(56-84)$ \\
Preoperative heparin (N) & $8(27.6 \%)$ & $8(25.8 \%)$ \\
\hline
\end{tabular}

Data are reported as means \pm SD or median (25th-75th percentile) and number (\%).

Table 2. Postoperative bleeding and transfusion data.

\begin{tabular}{lcc}
\hline & Tranexamic acid $(\mathrm{N}=29)$ & Placebo $(\mathrm{N}=31)$ \\
\hline Total blood loss $(\mathrm{mL})$ & $500(415-725)^{*}$ & $800(520-1050)$ \\
RBC (units/patient) & 0.48 & 0.71 \\
Patients transfused with RBC (\%) & 24 & 39
\end{tabular}

Data are reported as median (25th-75th percentile), number (\%) or as indicated. RBC $=$ red blood cells.

${ }^{*} \mathrm{P}<0.05$ compared to placebo (Mann-Whitney U-test). any coagulation variable (PT, aPTT, ACT, thrombin time, and fibrinogen) at any time point during the study. Plasma Ht levels in both groups decreased after $\mathrm{CPB}(\mathrm{P}=0.04)$. The aortic cross clamping, CPB time, anesthesia time, number and type of graft used were very similar in both groups.

Patients in the TA group had a significantly lower postoperative blood loss than the placebo group (Table 2). The placebo group had a greater median blood loss in the first $12 \mathrm{~h}(540(350-750) \mathrm{mL})$ than the TA group $(300(250-455) \mathrm{mL}), \mathrm{P}=0.001$. The placebo group also had greater blood loss at $24 \mathrm{~h}$ after surgery (800 (520-1050) vs 500 (415-725) $\mathrm{mL}, \mathrm{P}=0.008)$. Fourteen patients $(54.8 \%)$ in the placebo group lost more than $750 \mathrm{~mL}$ of blood postoperatively, vs 7 $(24.1 \%)$ in the TA group.

D-dimer levels were measured in 41 patients (22 in the placebo group and 19 in the TA group). Before CPB, the median concentration of D-dimer in both groups was within the laboratory's normal range, i.e., 190 (122306) $\mu \mathrm{g} / \mathrm{L}$ in the placebo group and 280 $(160-490) \mu \mathrm{g} / \mathrm{L}$ in the TA group. Three hours after completion of $\mathrm{CPB}$, the median Ddimer levels were 1057 (1025-1100) $\mu \mathrm{g} / \mathrm{L}$ in the placebo group and $520(435-837) \mu \mathrm{g} / \mathrm{L}$ in the TA group $(\mathrm{P}=0.01)$.

Postoperative transfusion details are shown in Table 2. No patient received platelets throughout the study and one patient in the placebo group received two units of fresh frozen plasma. Two patients were re-explored for excessive bleeding (one each in the placebo group and TA group). These patients were not excluded from the study. The patient in the TA group lost $2100 \mathrm{~mL}$ of blood and the other patient had no obvious bleeding point and lost $2700 \mathrm{~mL}$. There were 2 perioperative (postoperative) deaths in the placebo group, as opposed to none in the TA group. One of these two patients developed cardiogenic shock on the 2 nd postoperative day and the other had ventricular fibrillation on the 5 th postoperative day. There were no 
allergic reactions in either group. There were 2 perioperative myocardial infarctions in the placebo group, as opposed to none in the TA group. No patients in the TA group developed renal dysfunction and one patient in the placebo group had renal dysfunction, with death occurring after cardiogenic shock on the 2 nd postoperative day. No patients in the placebo group developed stroke, while there were two cases in the TA group.

\section{Discussion}

Three antifibrinolytic drugs, two synthetic ones, the lysine analogues $\varepsilon$-aminocaproic acid (EACA) and TA, and a natural one (aprotinin), are available for use in cardiac surgery. Administration of antifibrinolytics can reduce postoperative bleeding and minimize transfusion requirements. We chose a population of patients submitted to primary coronary artery grafting in order to determine if antifibrinolytic therapy is effective in a setting that usually does not involve excessive blood losses. Patients at particularly high risk of postoperative bleeding (history of hematological disorders, cardiac reoperation, antiplatelet therapy) were excluded from the study.

The efficacy of aprotinin is supported by numerous studies but the treatment for one patient is expensive and can be associated with anaphylactic reactions on reexposure, thus making the compound unsuitable for routine use in first-time procedures associated with the smallest risk of excessive postoperative blood loss. TA and EACA may be useful blood-sparing drugs in cardiac surgery. TA has greater efficacy, a longer halflife, stronger plasminogen binding, and a more sustained antifibrinolytic effect than EACA (10).

We administered TA before incision because of the rapid release of tissue plasminogen activator with subsequent fibrinolysis after skin incision (11). However, a study by Pleym et al. (12) showed that TA given over
5 min immediately before the start of CPB reduces postoperative bleeding in first-time CABG patients. The ideal dosage of TA remains controversial. The literature does not give precise indications. TA has been used in a wide range of doses. In the present study, the dose of $10 \mathrm{mg} / \mathrm{kg}$ followed by a continuous infusion of $1 \mathrm{mg} \mathrm{kg}^{-1} \mathrm{~h}^{-1}$ for $5 \mathrm{~h}$ was that used by Horrow et al. (13). Fiechtner et al. (14) reported that the dosing regimen of $10 \mathrm{mg} / \mathrm{kg}$ followed by a continuous infusion of $1 \mathrm{mg} \mathrm{kg}^{-1} \mathrm{~h}^{-1}$ results in adequate plasma concentrations to prevent fibrinolysis, with relatively stable drug levels throughout CPB. A recent study showed that the dose of $10 \mathrm{mg} / \mathrm{kg}$ followed by a continuous infusion of $1 \mathrm{mg} \mathrm{kg}^{-1} \mathrm{~h}^{-1}$ during the operation reduces postoperative bleeding (15). Antifibrinolytic treatment during the postoperative period does not reduce postoperative bleeding and routine prolongation of antifibrinolytic treatment is not indicated (16).

In the present prospective, double-blind, placebo-controlled study, we demonstrated that patients who were treated with TA had a $38 \%$ lower postoperative blood loss compared with patients who received placebo. The findings of the present study are consistent with other reports that illustrate the efficacy of TA in reducing blood loss after primary cardiac surgery $(17,18)$.

Although a trend was noted, the study was not sufficiently powered to show a significant difference in the likelihood of RBC transfusion.

Fibrinolysis has long been considered to be an important factor of postoperative bleeding. The lower plasma D-dimer levels in the TA group confirm that TA inhibited fibrinolysis, especially since D-dimer concentration is a sensitive quantitative measure of fibrinolysis (19). The D-dimer assay detects a plasmin-derived proteolytic fragment of cross-linked fibrin released by fibrinolytic activity. A recent study demonstrated that TA is effective in reducing bleeding through the prevention of fibrinolysis both in pa- 
tients undergoing $\mathrm{CABG}$ with $\mathrm{CPB}$ and in those undergoing $\mathrm{CABG}$ without $\mathrm{CPB}$ (20).

Strategies with antifibrinolytics to improve hemostasis during cardiac surgery may result in an increased risk of myocardial infarction. Dunn and Goa (8) did not report any study showing a greater incidence of thrombotic events in patients receiving TA. The low risk for intravascular thrombosis with TA may be important in patients undergoing CABG with a newly vascularized myocardium (21). Levi et al. (22), in a metaanalysis, showed that treatment with lysine analogues such as TA and EACA was not associated with an increased risk of perioperative myocardial infarction, but was associated with a trend towards a decrease in the frequency of this complication.

Laupacis and Ferguson (23), in a metaanalysis, reported that the use of aprotinin was associated with a non-significant increase in perioperative myocardial infarction (8vs 5.6\%). Another meta-analysis has shown that, although there was an almost identical overall myocardial infarction rate, the occurrence of infarction was $8.1 \%$ in patients treated with the conventional (high) doses of aprotinin compared with $3.9 \%$ in patients treated with lower doses $(\mathrm{OR}=$ $2.15,95 \% \mathrm{CI}=1.12-4.11)(22)$. A multicenter study for analysis of coronary graft patency after aprotinin reported that the use of aprotinin in patients having primary $\mathrm{CABG}$, in whom the primary distal target vessel was less than $1.5 \mathrm{~mm}$ in diameter or of poor quality, may adversely affect the vessel patency (24). This is important because the surgical patient is changing with the rise in interventional cardiology, and most patients have worse vessels. The inhibition of protein $\mathrm{C}$ and increase in thromboxane $\mathrm{A}_{2}$ production by aprotinin may be responsible for the potential increase in thrombotic complications related to aprotinin administration $(21,25)$.

Even with pooling, the number of randomized patients is insufficient to detect a significant difference in myocardial infarction with the use of antifibrinolytics. A large prospective controlled trial with myocardial infarction as the primary outcome will provide definitive evidence.

There were no statistical differences between TA and placebo treatment in terms of postoperative mortality and other complications such as allergic reaction, stroke, postoperative renal insufficiency, reopening rate, and convulsive seizures in the present study.

In conclusion, the study indicates that intraoperative use of tranexamic acid in patients undergoing coronary artery bypass grafting with cardiopulmonary bypass is effective in reducing postoperative blood loss and fibrinolysis. A large prospective randomized clinical trial is needed to confirm the safety of tranexamic acid.

\section{References}

1. Estafanous FG (1991). Bleeding hearts. Journal of Cardiothoracic and Vascular Anesthesia, 5 (Suppl 1): 2-3.

2. Moulton MJ, Creswell LL, Mackey ME et al. (1996). Reexploration for bleeding is a risk factor for adverse outcomes after cardiac operation. Journal of Thoracic and Cardiovascular Surgery, 111: 1037-1046.

3. Kojima T, Gando S, Kemmotsu O et al. (2001). Another point of view on the mechanism of thrombin generation during cardiopulmonary bypass: role of tissue factor pathway inhibitor. Journal of Cardiothoracic and Vascular Anesthesia, 15: 60-64.

4. Adelman B, Rizk A \& Hanners E (1988). Plasminogen interactions with platelets in plasma. Blood, 72: 1530-1535.
5. Spiess BD (1991). The contribution of fibrinolysis to bypass bleeding. Journal of Cardiothoracic and Vascular Anesthesia, 5 (Suppl): 13-17.

6. Boyle EM, Verrier ED \& Spiess BD (1997). The procoagulant response to injury. Annals of Thoracic Surgery, 64 (Suppl): 16-23.

7. Holloway DS, Summaria L, Sandesara J et al. (1988). Decreased platelet number and function and increased fibrinolysis contribute to postoperative bleeding in cardiopulmonary bypass patients. Thrombosis and Haemostasis, 59: 62-67.

8. Dunn CJ \& Goa KL (1999). Tranexamic acid. A review of its use in surgery and other indications. Drugs, 57: 1005-1032.

9. Hardy JF \& Desroches J (1992). Natural and synthetic antifibrinolyt- 
ics in cardiac surgery. Canadian Journal of Anaesthesia, 39: 353365.

10. Verstraete $M$ (1985). Clinical application of inhibitors of fibrinolysis. Drugs, 29: 236-261.

11. Mellbring G, Dahlgren S \& Wiman B (1985). Plasma fibrinolytic activity in patients undergoing major abdominal surgery. Acta Chirurgica Scandinavica, 151: 109-114.

12. Pleym H, Stenseth $R$, Wahba A et al. (2003). Single-dose tranexamic acid reduces postoperative bleeding after coronary surgery in patients treated with aspirin until surgery. Anesthesia and Analgesia, 96: 923-928.

13. Horrow JC, Van Riper DF, Strong MD et al. (1995). The dose response relationship of tranexamic acid. Anesthesiology, 82: 383392.

14. Fiechtner BK, Nuttall GA, Johnson ME et al. (2001). Plasma tranexamic acid concentrations during cardiopulmonary bypass. Anesthesia and Analgesia, 92: 1131-1136.

15. Zabeeda D, Medalion B, SverdLov M et al. (2002). Tranexamic acid reduces bleeding and the need for blood transfusion in primary myocardial revascularization. Annals of Thoracic Surgery, 74: 733738.

16. Casati V, Bellotti F, Gerli C et al. (2001). Tranexamic acid administration after cardiac surgery: a prospective, randomized, double blind, placebo controlled study. Anesthesiology, 94: 8-14.

17. Brown RS, Thwaites BK \& Mongan PD (1997). Tranexamic acid is effective in decreasing postoperative bleeding and transfusions in primary coronary artery bypass operations: a double-blind, randomized, placebo-controlled trial. Anesthesia and Analgesia, 85: 963970 .
18. Casati V, Guzzon D, Oppizzi M et al. (1999). Hemostatic effects of aprotinin, tranexamic acid and $\varepsilon$-aminocaproic acid in primary cardiac surgery. Annals of Thoracic Surgery, 68: 2252-2257.

19. Horrow JC, Hlavacek J, Strong MD et al. (1990). Prophylactic tranexamic acid decreases bleeding after cardiac operations. Journal of Thoracic and Cardiovascular Surgery, 99: 70-74.

20. Casati V, Gerli C, Franco A et al. (2004). Effects of tranexamic acid on postoperative bleeding and related hematochemical variables in coronary surgery: comparison between on-pump and off-pump techniques. Journal of Thoracic and Cardiovascular Surgery, 128: 8391.

21. Pinosky ML, Kennedy DJ, Fishman RL et al. (1997). Tranexamic acid reduces bleeding after cardiopulmonary bypass when compared to epsilon aminocaproic acid and placebo. Journal of Cardiovascular Surgery, 12: 330-338.

22. Levi M, Cromheecke ME, de Jonge E et al. (1999). Pharmacological strategies to decrease excessive blood loss in cardiac surgery: a meta-analysis of clinically relevant endpoints. Lancet, 354: 19401947.

23. Laupacis A \& Ferguson D (1997). Drugs to minimize blood loss in cardiac surgery: a meta-analysis using perioperative blood transfusion as the outcome. Anesthesia and Analgesia, 85: 1258-1267.

24. Alderman EL, Levy JH, Rich JB et al. (1998). Analyses of coronary graft patency after aprotinin use: results from the international multicenter aprotinin graft patency experience (IMAGE) trial. Journal of Thoracic and Cardiovascular Surgery, 116: 716-730.

25. Espana F, Estelles A, Griffin JH et al. (1989). Aprotinin is a competitive inhibitor of activated protein C. Thrombosis Research, 56: 751756 . 